Mustafa Emre Gürcü ๑ Atakan Erkılınç $\odot$ Değişiminin Postoperatif Akut Böbrek Hasarı ile İlişkisi

Fatih Yılmaz (D)

Tuncer Koçak (1)

\title{
The Relation of Intraoperative Renal Oxygen Saturation Change with Postoperative Acute Kidney Injury
}

Etik Kurul Onayı: Çalışma ileriye dönük bir çalışma olarak tasarlanmış ve Kurumsal Etik Kurulu tarafından onaylanmıștır (Protokol No: 2021 /4/482).

Çıkar Çatışması: Çıkar çatış̧ması yoktur.

Finansal Destek: Bu çalışma, herhangi bir fon tarafından desteklenmemiştir.

Hasta Onamı: Araștırmaya katılan tüm hastalardan, yasal bir vekilden, ebeveynlerden

veya küçük deneklerin yasal vasilerinden yazılı bilgilendirilmiş onam alındı.

Cite as: Yiğit Özay H, Demir A, Kaya Bahçecitapar M. Metabolik sendromlu koroner baypas hastalarında uygulanan iki farklı anestezi tipinin postoperatif karaciğer fonksiyonları üzerine etkisi. GKDA Derg. 2021;27(1):38-43.

Öz

Amaç: Akut böbrek hasarı, kardiyopulmoner baypas kullanılan açık kalp cerrahisinden sonra \%25-\%30 oranında görülen, postoperatif morbidite ve mortalteyi artırarak ameliyat başarısını azaltan en önemli bir faktördür. Near infrared spektroskopi (NIRS), beyin ve vital organlara oksijen sunumundaki dengesizliklerin erken belirlenmesi ve düzeltilmesine olanak sağlayan noninvaziv bir monitorizasyon yöntemidir. Bu çalışmanın amaCı, intraoperatif NIRS ile takip edilen renal $r \mathrm{SO}_{2}$ değerlerindeki değișikliklerin ameliyat sonrası gelișen akut böbrek hasarı ile ilişkisini araştırmaktır.

Yöntem: Temmuz 2020-Ocak 2021 tarihleri arasında kardiyopulmoner baypas kullanılarak açık kalp cerrahisi uygulanan 50 hasta çalışmaya dâhil edildi. Demografik veriler yaș, cinsiyet, vücut kitle indeksi (BMI) hipertansiyon, diabetes mellitus, kronik obstrüktif akciğer hastalığı ve bilinen kronik hastalıklar, sol ventrikül ejeksiyon fraksiyonunu içermektedir. Akut böbrek hasarı tanımı KDiGO kriterlerine göre tanımlandı. Postoperatif 48. saat sonunda akut böbrek hasarı gelisen ve gelismeyen hastaların, intraoperatif renal rSO değişimleri ile ilişkisi değerlendirildi.

Bulgular: Çalışmaya dâhil edilen 50 hastanın yaş ortalaması 62 (54.3-66,5) idi ve çoğunluğu erkek hastay $d_{\imath}(\% 72)$. Intraoperatif verilerin değerlendirilmesinde, renal $\mathrm{rSO}_{2}$ değişiminin ameliyat sonrası akut böbrek hasarı gelişen ve gelişmeyen (sırasıyla; -\%12, -\%3) hastalar arasında istatistiksel olarak anlamlı farklılık olduğu saptandı (p:0.001). Penalised multivarite logistic regresyon analizinde de intraoperatif rSO değerindeki değisimlerin [(from -\%10 to \%0,5), OR: $0.18(0,04-0,76) \mathrm{p:} 0,03$ ] postoperatif akut böbrek hasarı gelişimi için bağımsız bir öngördürücü olduğu bulundu.

Sonuç: KBP döneminde takip edilen renal rSO ölçümlerindeki düsüslerin postoperatif dönemdeki akut böbrek hasarı gelişimini predikte ettiğini saptadık. NIRS ile renal oksijen saturasyon monitorizasyonunun, hem noninvaziv olması hem de eş zamanlı verileri yansıtması postoperatif dönemdeki renal disfonksiyonun öngörülebilmesi için oldukça etkili bir yöntem olduğunu düşünmekteyiz.

Anahtar kelimeler: akut böbrek hasarı, renal $\mathrm{rSO}_{2}$, kardiyopulmoner baypas

ABSTRACT

Objective: Acute kidney injury seen in 25-30\% of the cases after open heart surgery where cardiopulmonary bypass was performed, is one of the most important factors that affect the success of the on-pump open heart surgery by increasing the rates of postoperative morbidity, and mortality. Near infrared spectroscopy (NIRS) is a noninvasive monitoring that frequently used method that allows correction of imbalances in oxygen supply to the brain and vital organs. We aimed to investigate the relationship between renal oxygen saturation values and postoperative acute kidney injury.

Method: Fifty patients who underwent on- pump open heart surgery between July 2020 and January 2021 by using cardiopulmonary bypass were included in the study. Demographic data included age, gender, body mass index (BMI), hypertension, diabetes mellitus, chronic obstructive pulmonary disease, other chronic diseases and left ventricular ejection fraction. The definition of acute kidney injury was defined according to the criteria of KDIGO. At the end of the postoperative 48th hour the relationship between intraoperative renal $r \mathrm{SO}_{2}$ changes in patients with or without acute kidney injury was evaluated.

Results: Fifty patients were included in the current study. The median (IQR) age of 50 patients was 62 (54.366.5), and mostly male patients constituted the study populatio,. When we evaluated the intraoperative data, there were statistically significant differences in changes in renal $\mathrm{rSO}$ values in patients who had and had not developed postoperative acute kidney injury (-12\%, $-3 \%$, respectively) ( $p$ : 0.001$)$. In the multivariate logistic regression analysis, the change in $r S O$ values in the intraoperative period [(from-10\% to $0.5 \%$ ), OR: $0.18(0.04-0.76) \mathrm{p}: 0.03]$ were found to be an independent predictor of postoperative acute kidney injury. Conclusion: We found that the decrease of renal $\mathrm{rSO}_{2}$ measurements during surgery may predict the development of acute kidney injury in the postoperative period. We think that renal oxygen saturation monitoring with NIRS is a very effective method for predicting postoperative renal dysfunction, because it is both noninvasive and reflects simultaneous data.

Keywords: acute kidney Injury, renal $\mathrm{SSO}_{z^{\prime}}$ cardiopulmonary bypass
Received/Geliş: 22.01 .2021

Accepted/Kabul: 22.02.2021

Published Online/Online yayın: 23.03.2021

Mustafa Emre Gürcï

Kartal Koşuyolu Yüksek İhtisas Eğitim ve Araștirma Hastanesi Anesteziyoloji ve Reanimasyon Kliniği

İstanbul - Türkiye emregurcu@gmail.com ORCiD: 0000-0002-5434-9932

A. Erkılınç 0000-0002-8736-6085 P. Karaca Baysal 0000-0002-5187-8679

T. Koçak 0000-0002-6428-8694 Kartal Koșuyolu Yüksek ihtisas Eğitim ve Araştirma Hastanesi Anesteziyoloji ve Reanimasyon Kliniği istanbul, Türkiye Kartal Koşuyolu Yüksek Ihtisas Eğitim ve Araştırma Hastanesi, Kardiyoloji Kliniği Istanbul, Türkiye
F. Yılmaz 0000-0002-8439-0426

(C) Telif hakkı Göğüs Kalp Damar Anestezi ve Yoğun Bakım Derneği'ne aittir. Logos Tıp Yayıncılık tarafindan yayınlanmaktadır Bu dergide yayınlanan bütün makaleler Creative Commons Attf-Gayri Ticari 4.0 Uluslararası Lisansı ile lisanslanmıştır. 


\section{Giriş}

Akut böbrek hasarı (ABH), kardiyopulmoner baypas (KPB) kullanılan açık kalp cerrahisinden sonra \%25-\%30 oranında görülen ${ }^{[1]}$, postoperatif morbidite ve mortalteyi artırarak ameliyat başarısını azaltan en önemli faktörlerdendir. Ameliyat öncesi $\mathrm{ABH}$ gelişimini tahmin etmeye yardımcı olacak birtakım faktörlerin yanında, ameliyat sırasında özellikle KPB'ta, $\mathrm{ABH}$ gelişmesinin tahmin edilerek gerekli tedavi ve müdahalenin yapılması, $\mathrm{ABH}$ 'nın neden olacağı morbidite ve mortaliteyi azaltıp, ameliyat başarını artıracaktır.

ABH gelişimini tahmin etmede birçok laboratuvar ve biyobelirteçlerden yararmaktadır. Serum kreatin ( $\mathrm{sCr}$ ) seviyelerindeki küçük artışlar böbrek hasarını ve kötü klinik sonuçları gösterebilir. Fakat $s C r$ 'deki artışlar ABH'nın başlangıç dönemlerinde olmayacağı için $A B H$ gelişim riskinin erken tanısında sınırlı değere sahiptir ${ }^{[2]}$. Açık kalp cerrahisi sonrası $\mathrm{ABH}$ gelişimini önlemek için, renal hipoksinin derecesinin belirlenmesi ve gerçek zamanlı olarak monitörize edilmesi oldukça önemlidir. Near infrared spektroskopi (NIRS), doku hemoglobin saturasyonunun invivo analizinde sıklıkla kullanılan, beyin ve vital organlara oksijen sunumundaki dengesizliklerin erken saptanması ve düzeltilmesine olanak sağlayan noninvaziv bir monitorizasyon yöntemidir [3]. Bölgesel bir doku alanındaki oksijenize ve deoksijenize hemoglobin arasındaki farkı anlık ve sürekli olarak ölçer, böylece bölgesel oksijen saturasyonu hakkında klinisyene sürekli bilgi verir ${ }^{[4]}$.

Bu çalışmanın amacı, intraoperatif NIRS ile takip edilen renal $\mathrm{rSO}_{2}$ değerlerindeki değişikliklerin ameliyat sonrası gelişen $\mathrm{ABH}$ ile ilişkisini araştırmaktır.

\section{GEREÇ ve YÖNTEM}

Kurumsal etik kurul onayı alındıktan sonra Temmuz 2020-Şubat 2021 tarihleri arasında kardiyopulmoner baypas kullanılarak açık kalp cerrahisi uygulanan 50 hasta çalışmaya dâhil edildi. Çalışmaya dâhil edilme kriterleri; 18 yaş üstü, sol ventrikül ejeksiyon fraksiyonu (EF) $>\% 30$, normal preoperatif $\mathrm{sCr}(<1.2 \mathrm{mg} /$ $\mathrm{dL}$ ), elektif açık kalp cerrahisi geçiren hastalar idi. Çalışma dışı bırakılma kriterleri; acil ve/veya revizyon ameliyatı olan hastalar, mekanik destek cihazı ile ameliyata alınanlar, vücut kitle indeksi (BMi) $>32 \mathrm{~kg} /$ $\mathrm{m}^{2}$ olan, cilt-böbrek mesafesi $>4 \mathrm{~cm}$ 'den fazla olanlar, son dönem böbrek hastalığı olan veya böbrek nakli olan hastalar olarak belirlendi.

Anestezi indüksiyonu fentanil (5 ila $10 \mathrm{mcg} / \mathrm{kg}$ ), propofol (1-2 mg/kg) ve ardından oral trakeal entübasyon roküronyum $(0,5 \mathrm{mg} / \mathrm{kg})$ ile sağlandı. Ameliyat süresince anestezi aralıklı bolus fentanil, dormicum, roküronyumun intravenöz yinelenmesi ve sevofluran ile sağlandı. Heparinizasyon $(3 \mathrm{mg} / \mathrm{kg}$ ) sonrası yeterli aktive pıhtılaşma zamanı (ACT) (>400 saniye) sağlandıktan sonra aort kanülasyonu ve ardından sağ atriyum veya selektif bikaval kanülasyon yapılarak KPB başlatıldı. Kardiyopulmoner baypasta $2.4 \mathrm{~L} / \mathrm{dk} . / \mathrm{m}^{2}$ olacak şekilde perfüzyon sağlandı. Hedef ortalama arter basıncı $>60 \mathrm{mmHg}$ ve hemoglobin değeri $>7$ $\mathrm{mg} / \mathrm{dL}$ olarak belirlendi. Hastalar ortalama $30-32^{\circ} \mathrm{C}^{\prime} \mathrm{ye}$ soğutuldu. Cerrahi işlemin bitmesinden sonra hastalar $37^{\circ} \mathrm{C}$ 'ye ısıtıldı. Hemodinamik stabilizasyon (ortalama arter basıncl $>60 \mathrm{mmHg}, \mathrm{Htc}>24 \mathrm{~g} / \mathrm{dL}$, hasta ISISI $>36,5^{\circ} \mathrm{C}$, malign aritmi yok) sağlandıktan sonra KPB'tan ayrıldı. Heparin, protamin ile nötralize edildi. Kanama kontrolü yapılıp, sternum kapatıldıktan sonra hastalar yoğun bakım ünitesine entübe olarak transfer edildi.

Demografik veriler yaş, cinsiyet, vücut kitle indeksi (VKi), hipertansiyon, diabetes mellitus, kronik obstrüktif akciğer hastalığı ve bilinen kronik hastalıklar, sol ventrikül ejeksiyon fraksiyonunu içermektedir. Ameliyat öncesi $\mathrm{sCr}$, üre ve glomerüler filtrasyon oranları (GFR) [eGFR= $186 *$ kreatin $^{-1.154} *$ yaş $^{-0.203 *}$ 0.742 (kadın hasta)] kaydedilen hastalara, anestezi indüksiyonundan önce NIRS sensörleri (INVOS 5100C, Medtronic) USG rehberliğinde hastaların T12-L2 seviyesinde her iki böbrek bölgesine yerleştirilerek renal $\mathrm{rSO}_{2}$ bazal değerleri kaydedildi. Ameliyat süresince, en düşük renal $\mathrm{rSO}_{2}$ ve en yüksek NIRS düşüş yüzdesi belirlendi. Ameliyat süresince ortalama arter basınçları, KPB'ta vücut ISISI, en düşük hemoglobin ve renal $\mathrm{rSO}_{2}$ değerleri, aortik kros klemp süreleri, perfüzyon ve ameliyat süreleri, ameliyat sonrası 24 . saat $\mathrm{sCr}$, üre, GFR, yoğun bakım kalış süreleri kaydedildi Akut böbrek hasarı KDiGO (24-48 saat içinde serum kreatininde $>0.3 \mathrm{mg} / \mathrm{dL}(>26,5 \mathrm{~mol} / \mathrm{l})$ artış veya son 7 gün içinde serum kreatininde başlangıç değerinin $>1,5$ kat artış, 6 saat süreyle idrar hacmi $<0,5 \mathrm{ml} / \mathrm{kg} /$ saat) kriterlerine göre tanımlandı ${ }^{[5]}$. Hastalar, posto- 
peratif 24-48 saat içinde, $A B H$ gelişen $(A B H(+))$ ve $A B H$ gelişmeyen $(\mathrm{ABH}(-))$ olmak üzere iki gruba ayrıldı.

\section{İstatistik}

Sürekli değişkenler medyan ve çeyrekler arası aralık (interquartile range (IQR)) [\%2 $\left.5^{\text {th }}-\% 75^{\text {th }}\right]$ olarak sunuldu. Sayısal veriler için iki grup karşılaştırmasında Mann-Whitney U testi kullanıldı. Kategorik değişkenler sayı ve yüzde olarak sunuldu. Kategorik değişkenler için uygun olan Yates düzeltmeli ki-kare testi ve Fisher's Exact testi ile karşılaştırıldı.

Prosedür sonrası nefropati (PPN): Genel bir kural olarak, modele dâhil edilen öngörücülerin serbestlik derecelerine göre her öngördürücü için en az 10 hasta olmalıdır (sonuç/degrees of freedom $\mathrm{n}$ : 10). PPN multivariate modelimizde, 11 hastada $(11 / 3=3,5)$ sonlanım varken 3 öngördürücü belirlendi. Bu nedenle PPN ve 3 aday belirleyici arasındaki aşırı-uyum riski nedeni ile model yaparak ilişkiyi değerlendirmek için penalized multivariate lojistik regresyon yöntemi kullanılmıştır. Penalized multivariate regresyon modelimizde, Yaş, renal $\mathrm{rSO}_{2}$ değişimi ve preoperatif sCr değişkenleri alındı. Regresyon modelinde sürekli değişkenler çeyrekler arası aralık olarak daha rahat anlaşılması amacı ile raporlama yöntemi olarak kullanıldı. Ayrıca regresyon modelindeki renal $\mathrm{rSO}_{2}$ değişiminin added Variable plot kullanılarak (modeldeki diğer değişkenler ile düzeltme yapılarak) sürekli değişkenin nonlineer hali log-odds olarak sunuldu.

Tablo 1. Demografik veriler.

\begin{tabular}{lccc} 
& $\begin{array}{c}\text { ABH (-) } \\
(\mathbf{n}: 39)\end{array}$ & $\begin{array}{c}\text { ABH (+) } \\
(\mathbf{n}: 11)\end{array}$ & p \\
\hline Yaş (yıl) & $58(53.5-67)$ & $65(56.5-66)$ & 0.367 \\
Cins & & & \\
$\quad$ Erkek & $28(\% 71.8)$ & $8(\% 72.7)$ & 0.951 \\
$\quad$ Kadın & $11(\% 28.2)$ & $3(\% 27.3)$ & \\
VKi (kg/m²) & $26.9(24.5-28.7)$ & $26.6(24.1-28.5)$ & 0.994 \\
HT & $24(\% 61.5)$ & $7(\% 63.6)$ & 0.899 \\
DM & $17(\% 43.6)$ & $3(\% 27.3)$ & 0.329 \\
KOAH & $3(\% 7.7)$ & 0 & 0.466 \\
EF (\%) & $60(60-65)$ & $60(5-60)$ & 0.114 \\
ÜRE (mg/dL) & $37(31-44)$ & $36(27-47.5)$ & 0.799 \\
sCr (mg/dL) & $0.8(0.73-0.92)$ & $0.8(0.73-0.92)$ & 0.494 \\
GFR & $94(76.9-108)$ & $103(87.5-108)$ & 0.731 \\
& & &
\end{tabular}

VKi: vücut kitle indeksi, HT: hipertansiyon, DM: diabetes mellitus, KOAH: kronik obstrüktif akciğer hastalığı, EF: sol ventrikül ejeksiyon fraksiyonu, sCr: serum kreatini, GFR: glomerüler filtrasyon oranı.
Tüm istatistiksel analizler, R versiyon 4.01 (R Project, Viyana, Avusturya) ile "rms", "Hmisc" ve "ggplot2" paketleri kullanılarak gerçekleştirildi.

\section{BULGULAR}

Hastaların demografik bulguları Tablo 1'de özetlenmiştir. Çalışmaya dâhil edilen 50 hastanın yaş ortalaması $62(54.3-66,5)$ idi ve çoğunluğu erkekti 36 (\%72). Hastaların hepsi koroner arter baypas greft ameliyatı (KABG) geçiren hastalardı. Hastaların 11'de (\%22) ameliyat sonrası evre 1 $\mathrm{ABH}$ gelişti. Bu hastaların hiçbirinde renal replasman tedavisine gerek duyulmadı ve medikal tedavi ve uygun sıvı replasmanları ile böbrek hasarları düzeltildi. Hasta karakteristikleri ve ameliyat öncesi laboratuvar değerleri açısından iki grup arasında farklılık yoktu.

Intraoperatif verilerin değerlendirilmesinde, renal $\mathrm{rSO}_{2}$ değişiminin ameliyat sonrası $\mathrm{ABH}$ gelişen ve gelişmeyen (sırasıyla; -\%12, -\%3) hastalar arasında istatistiksel olarak anlamlı farklılık olduğu saptandı (p:0.001) (Tablo 2).

Yapılan univariate analizde $\mathrm{rSO}_{2}$ değişiminin [(from -\%10 to \%0,5), OR:0.21 (0.06-0.78) p:0.044] postoperatif $A B H$ gelişimini öngörmede istatistiksel olarak anlamlı bulundu. Diğer bulgular Tablo 3'te verilmiştir.

\section{Tablo 2. Intraoperatif veriler.}

\begin{tabular}{|c|c|c|c|}
\hline & $\begin{array}{l}\text { ABH (-) } \\
(\mathrm{n}: 39)\end{array}$ & $\begin{array}{l}\text { ABH (+) } \\
(\mathrm{n}: 11)\end{array}$ & $p$ \\
\hline $\begin{array}{l}\text { En düşük } \\
\text { Hemoglobin (g/dL) }\end{array}$ & $8(7.25-8.45)$ & $7.2(6.90-7.95)$ & 0.093 \\
\hline $\begin{array}{l}\text { Ortalama Arter } \\
\text { Basıncı (mmHg) }\end{array}$ & $65(60-74.5)$ & $70(62.5-70)$ & 0.843 \\
\hline En düşük ISI $\left({ }^{\circ} \mathrm{C}\right)$ & $31(30-32)$ & $30(30-30)$ & 0.066 \\
\hline $\begin{array}{l}\text { Sol Renal rSO } \\
\text { (NIRS sol) }\end{array}$ & $72(58-90)$ & $68(54-88)$ & 0.559 \\
\hline $\begin{array}{l}\text { Sağ Renal rSO } \\
\text { (NIRS sağ) }\end{array}$ & $71(57-88)$ & 65 (52-90) & 0.744 \\
\hline $\begin{array}{l}\text { Renal rSO } \\
\text { değişimi (\%) }\end{array}$ & $-3(-7.5 ; 3.5)$ & $-12(-17 ;-5)$ & 0.001 \\
\hline
\end{tabular}




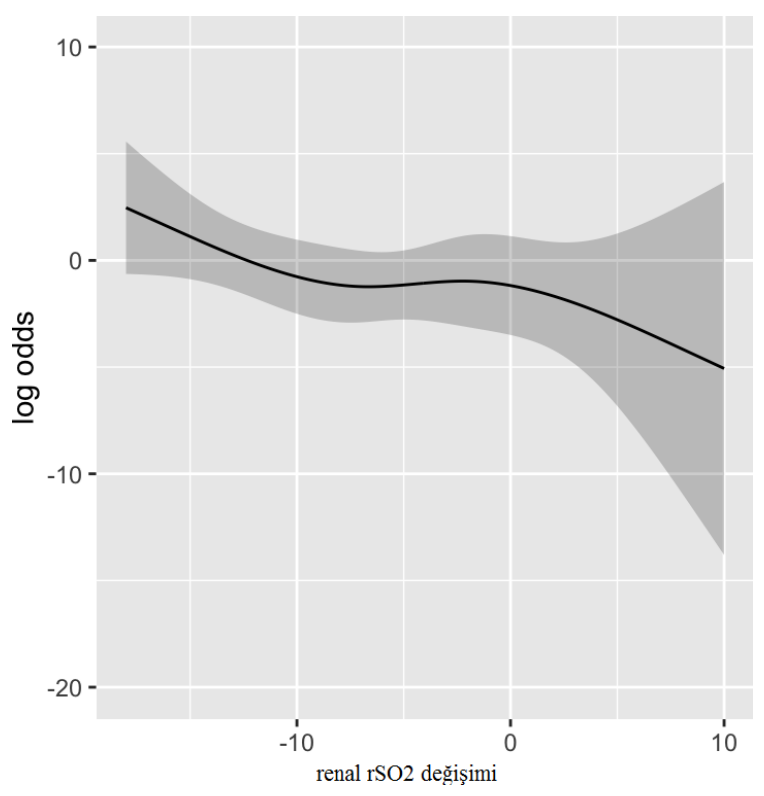

Şekil 1. Düzenlenmiş öngördürücü plotu.

Postoperatif $A B H^{\prime}$ ı̈ öngörmede renal $r \mathrm{SO}_{2}$ 'nin değişimi ile oluşan karşılıklı etkileşim.

Tablo 3. Univarite logistik regresyon analiz.

\begin{tabular}{lccc} 
& OR & \%95 Cl & p \\
\hline $\begin{array}{l}\text { sCr (mg/dL) } \\
(0.74-0.9)\end{array}$ & 1.39 & $0.61-3.17$ & 0.49 \\
$\begin{array}{l}\text { Yaş (yıl) } \\
(54-66)\end{array}$ & 2.45 & $0.49-12$ & 0.08 \\
$\begin{array}{l}\text { Renal rSO }{ }_{2} \text { değişimi (\%) } \\
(-10-0.5)\end{array}$ & 0.21 & $0.06-0.78$ & $0.044 *$ \\
$\begin{array}{l}\text { AKK Süresi (dakika) } \\
(60-93)\end{array}$ & 1.75 & $0.61-5.01$ & 0.24 \\
$\begin{array}{l}\text { Perfüzyon süresi (dakika) } \\
(91.25-139.75)\end{array}$ & 2.03 & $0.54-7.62$ & 0.36 \\
$\begin{array}{l}\text { Hemoglobin (g/dL) } \\
(7.1-8.3)\end{array}$ & 0.41 & $0.14-1.18$ & 0.09 \\
& & & \\
\hline
\end{tabular}

sCr: serum kreatini, AKK: aortik kros klemp

Ayrıca penalised multivarite logistic regresyon analizinde de intraoperatif $\mathrm{rSO}_{2}$ değerindeki değişimlerin [(from -\%10 to \%0,5), OR:0.18 (0.04-0.76) p:0.03] postoperatif $A B H$ gelişimi için bağımsız bir öngördürücü olduğu bulundu. Düzenlenmiş öngördürücü plot'da postoperatif $\mathrm{ABH}$ gelişme riskinin renal $\mathrm{rSO}_{2}$ değerindeki \%7 düşmeden sonra arttığı gösterildi. Diğer bulgular Tablo 4 ve Şekil 1'de gösterilmiştir.
Tablo 4. Penalised multivarite logistik regresyon analiz.

\begin{tabular}{lccc} 
& Odds ratio & $\% 95 \mathrm{Cl}$ & $\mathbf{p}$ \\
\hline $\begin{array}{l}\mathrm{s} C r(\mathrm{mg} / \mathrm{dL}) \\
(0.74-0.9)\end{array}$ & 1.30 & $0.66-2.57$ & 0.81 \\
$\begin{array}{l}\text { Yaş (yıl) } \\
(54-66)\end{array}$ & 1.42 & $0.53-3.76$ & 0.09 \\
$\begin{array}{l}\text { Renal rSO } \\
(-10-0.5)\end{array}$ & 0.18 & $0.04-0.76$ & $0.03^{*}$ \\
\hline
\end{tabular}

sCr: serum kreatini

Tablo 5. Intraoperatif-postoperartif süreler.

\begin{tabular}{|c|c|c|c|}
\hline & $\begin{array}{l}\text { ABH (-) } \\
(\mathrm{n}: 39)\end{array}$ & $\begin{array}{c}\mathrm{ABH}(+) \\
(\mathrm{n}: 11)\end{array}$ & $p$ \\
\hline $\begin{array}{l}\text { AKK süresi } \\
\text { (dakika) }\end{array}$ & $\begin{array}{c}72 \\
(59-93)\end{array}$ & $\begin{array}{c}80 \\
(71-92)\end{array}$ & 0.680 \\
\hline $\begin{array}{l}\text { Perfüzyon süresi } \\
\text { (dakika) }\end{array}$ & $\begin{array}{c}114 \\
(90-136)\end{array}$ & $\begin{array}{c}121 \\
(105-157)\end{array}$ & 0.293 \\
\hline $\begin{array}{l}\text { Ameliyat süresi } \\
\text { (saat) }\end{array}$ & $\begin{array}{c}4 \\
(3.75-5)\end{array}$ & $\begin{array}{c}4.5 \\
(3.5-5.72)\end{array}$ & 0.594 \\
\hline $\begin{array}{l}\text { Yoğun bakım süresi } \\
\text { (gün) }\end{array}$ & $\begin{array}{c}2 \\
(2-3)\end{array}$ & $\begin{array}{c}2 \\
(2-3)\end{array}$ & 0.645 \\
\hline
\end{tabular}

AKK: aortik kros klemp

Hastaların intraoperatif (AKK, perfüzyon ve ameliyat süreleri) ve postoperatif (yoğun bakım kalış) süreleri arasında, $\mathrm{ABH}$ gelişen hastalarla gelişmeyen hastalar arasında anlamlı bir fark bulunamadı (Tablo 5).

\section{TARTIŞMA}

Açık kalp cerrahisi sonrası $A B H$ gelişimini öngördürücü faktörlerin incelendiği bu çalışmanın ana sonucu olarak, NIRS monitörü ile sürekli takip edilen intraoperatif renal $\mathrm{rSO}_{2}$ değerlerindeki düşme ameliyat sonrası $\mathrm{ABH}$ gelişimi ile anlamlı olarak ilişkili olduğu bulunmuştur.

Kardiyopulmoner baypas ile birlikte yapılan açık kalp cerrahisi, emboli, düşük perfüzyon, nonpulsatil akım, dilüsyonel anemi, inflamatuar mediatör salınımı, arteriyel oksijen sunumunun azalması gibi nedenlerle $\mathrm{ABH}$ gelişimine neden olabilir ${ }^{[6,7]}$. Ameliyat sonrası gelişen $A B H$ yüksek morbidite ve mortalite ilişkilidir 
${ }^{[6,8]}$. Gelişebilecek $A B H^{\prime}$ nın erken saptanması, etkene yönelik tedavinin şekillenmesine ve ameliyat başarısını artırmaya yardımcı olacaktır. Serum kreatin seviyesi ABH'nın teşhisi için hâlâ en sık kullanılan parametre olmasına rağmen, $A B H$ gelişen hastalarda yavaş ve geç yükseliyor olması farklı öngördürücü parametrelerin kullanılmasını gerektirmektedir. Literatürde, üriner biyobelirteçlerin (NGAL, IL-18 ve sistatin C) ve renal NIRS'nin, postoperatif erken dönemde pediatrik kardiyak cerrahiden sonra $A B H$ gelişimini tahmin etmede önemli parametereler olduğunu bildiren çalışmalar olmasının yanında, biyobelirteçlerin aksine NIRS monitorizasyonu doku saturasyonunun özellikle gerçek zamanlı noninvaziv takibine olanak sağlamaktadır ${ }^{[9]}$. Kardiyovasküler cerrahi anestezi yönetiminde NIRS ilk olarak serebral $\mathrm{rSO}_{2}$ takibinde kullanılsa da, günümüzde artık renal $\mathrm{rSO}_{2}$ 'daki düşüşler tıpkı postoperatif kognitif disfonksiyonların belirlenmesinde olduğu gibi postoperatif $A B H$ gelişimini öngörmede kullanılmaktadır ${ }^{[2]}$. Erişkin hasta grubunda yapılan az sayıda çalışma, KPB'ta NIRS monitorizasyonuyla takip edilen renal $\mathrm{rSO}_{2}$ değerlerindeki düşmelerin ameliyat sonrası gelişen $A B H^{\prime} n ı$ önemli ölçüde tahmin ettiği bildirilmiştir ${ }^{[9]}$. Özellikle başlangıç değerlerine göre \%20'nin üzerindeki azalmaların $\mathrm{ABH}$ gelişimi için daha anlamlı olduğu bulunmuştur ${ }^{[10]}$. Ayrıca, renal $\mathrm{rSO}_{2}$ ölçümü, invaziv olarak ölçülen renal ven oksijen satürasyonundaki değişiklikler ile koreledir ve perioperatif dönemde renal oksijenasyonunu gösteren bir belirteç olarak kullanılabilir ${ }^{[11]}$. Çalışmamız sırasında, hastalar özellikle KPB döneminde hemodinamik olarak ve belirli aralıklarla alınan arteriyel kan gazı örnekleriyle yakın monitorize edildi. Uç organ perfüzyonu ve doku oksijen saturasyonunun göstergesi olarak monitorize edilen NIRS değerlerindeki belirgin düşmelerde (>\%15-20), hemodinamik parametreler pompa debisi artırılarak veya vazopressor/inotrop ilaçlarla desteklendi, arteriyel kan gazı sonuçlarına göre özellikle hemoglobin düzeylerinin $7 \mathrm{~g} / \mathrm{dL}$ 'nin üzerinde olmasını sağlama amacıyla kan replasmanları yapıldı. Çalışmamız sonuçlarında da yapılan bu müdahalelere rağmen, perioperatif dönemde renal $\mathrm{rSO}_{2}$ değerlerindeki düşmelerin özellikle \%7 ve üzerindeki NIRS düşmelerinin ameliyat sonrası gelişen $\mathrm{ABH}$ ile yakından ilişkili olduğu belirlendi. li risk faktörlerinden birisi preoperatif $\mathrm{s} C r$ değeridir. Serum $\mathrm{Cr}$ değerinin 2-4 mg/dl arasında olan hastalarda $\mathrm{ABH}$ gelişim riski yaklaşık \%10-20 iken, $4 \mathrm{mg} /$ dl üzerinde \%25-28 arasındadır [12,13]. Cerrahi tipi (kapak cerrahisi), peroperatif kanama miktarı, acil uygulanan cerrahi gibi risk faktörlerinin yanında, özellikle aortik kros klemp süresi, KPB süreleri ve normotermik-hipotermik baypas gibi özellikle düşünülmesi gereken risk faktörleri vardır. Ameliyat öncesi normal böbrek fonksiyonlarının olduğu hastalarda KBP süresinin uzun olması, KBP sırasında ortalama arteriyel basıncın $60 \mathrm{mmHg}$ 'nın altında uzun süre seyretmesi $A B H$ gelişimi ile yakından ilişkili olduğu bildirilmiştir ${ }^{[14,15]}$. Bu bilgilerin aksine bazı çalışmalarda ise AKK ve perfüzyon sürelerinin $\mathrm{ABH}$ gelişimi ile herhangi bir ilişkinin olmadığı söylenmiştir ${ }^{[16]}$. Çalışmamızın sonuçlarına göre, AKK ve $\mathrm{KPB}$ süreleri $\mathrm{ABH}$ gelişen grupta daha uzun olsa da istatistiksel bir anlamlılık bulunamamıştır. Ayrıca ameliyat sonrası $\mathrm{ABH}$ gelişen hastalarla, gelişmeyen hastaların ameliyat öncesi $\mathrm{s} C r$ değerleri arasında da herhangi bir fark yoktu. Çalışmalarda ileri yaş ve normotermik KPB'ın postoperatif $\mathrm{ABH}$ için prognostik faktör olarak gösterilmiştir ${ }^{[17]}$. Çalışmamızdaki tüm hastalarda KPB hafif hipotermi altında yapılmış olup, $A B H$ gelişen ve gelişmeyen hastaların yaşları arasında farklılık yoktu. Yine yoğun bakım süreleri arasında da iki grup arasında bir farklılık saptanmadı.

Bu çalışmadaki kısıtlamalar; hasta sayısının az olma$\mathrm{SI}$, postoperatif dönemde renal $\mathrm{rSO}_{2}$ ölçümlerinin yapılamamış olması ve KPB sırasında anestezi yönetimi standardize edilebilmesine rağmen, farklı cerrahi ekipler tarafından yapılan ameliyatların cerrahi invazivliğinin değişken olmasıdır.

Sonuç olarak, çalışmamızda; KPB döneminde NIRS ile renal oksijen saturasyonunun monitorizasyonu, hem noninvaziv olması hem de eşzamanlı verileri yansıtması ile renal $\mathrm{rSO}_{2}$ değerlerindeki düşüşlerin postoperatif dönemdeki $A B H$ gelişimini öngörmede etkili bir yöntem olabileceğini belirledik. NIRS monitorizasyon yönteminin ameliyat sonrası $\mathrm{ABH}$ gelişimini öngörücü olduğunu desteklemek için daha çok sayıda hasta ile yapılacak çalışmalara gereksinim olduğu düşüncesindeyiz. 


\section{KAYNAKLAR}

1. Jiachang $\mathrm{H}$, Rongyi $\mathrm{C}$, Shaopeng $\mathrm{L}$, Xiaofang $\mathrm{Y}$, Jianzhou Z, Xiaoqiang D. Global incidence and outcomes of adult patients with acute kidney injury after cardiac surgery: A systematic review and meta-analysis. Cardiothorac Vasc Anesth. 2016 Jan; 30(1):82-9.

https://doi.org/10.1053/j.jvca.2015.06.017

2. Dae-Kee C, Wook-Jong K, Ji-Hyun C, Eun-Ho, Kyung Don $\mathrm{H}$, Ji Yeon S, In Cheol C. Intraoperative renal regional oxygen desaturation can be a predictor for acute kidney injury after cardiac surgery. Cardiothorac Vasc Anesth. 2014 Jun;28(3):564-71. https://doi.org/10.1053/j.jvca.2013.12.005

3. Booth EA, Dukatz C, Ausman J, Wider M. Cerebral and somatic venous oximetry in adults and infants. Neurol Int. 2010 Nov 27; 1:75 https://doi.org/10.4103/2152-7806.73316

4. Olbrecht VA, Skowno J, Marchesini V, Ding L, Jiang Y, Ward CG, et al. An international, multicenter, observational study of cerebral oxygenation during infant and neonatal anesthesia. Anesthesiology. 2018 Jan;128(1):85-96. https://doi.org/10.1097/ALN.0000000000001920

5. Mehta RL, Kellum JA, Shah SV, Molitoris BA, Ronco C, Warnock DG, Levin A: Acute kidney injury network: report of an initiative to improve outcomes in acute kidney injury. Crit Care 2007;11:R31. https://doi.org/10.1186/cc5713

6. Karkouti K, Wijeysundera DN, Yau TM, Callum JL, Cheng DC, Crowther $\mathrm{M}$, et al. Acute kidney injury after cardiac surgery: focus on modifiable risk factors. Circulation. 2009 Feb 3;119(4):495-502.

https://doi.org/10.1161/CIRCULATIONAHA.108.786913

7. Stafford-Smith M, Patel UD, Phillips-Bute BG, Shaw AD, Swaminathan M. Acute kidney injury and chronic kidney disease after cardiac surgery. Adv Chronic Kidney Dis. 2008 Jul;15(3):257-77. https://doi.org/10.1053/j.ackd.2008.04.006

8. Hobson CE, Yavas S, Segal MS, Schold JD, Tribble CG, Layon AJ, Bihorac A. Acute kidney injury is associated with increased long-term mortality after cardiothoracic surgery. Circulation 119:2444-53, 2009. Circulation. 2009 May 12;119(18):2444-53. https://doi.org/10.1161/CIRCULATIONAHA.108.800011

9. Hazle MA, Gajarski RJ, Aiyagari R, Yu S, Abraham A, Donohue J, Blatt NB. Urinary biomarkers and renal near-infrared spectroscopy predict intensive care unit outcomes after cardiac surgery in infants younger than 6 months of age. J Thorac Cardiovasc Surg. 2013
Oct;146(4):861-7.e1. https://doi.org/10.1016/j.jtcvs.2012.12.012

10. Christian Ortega-Loubon, MD, MEd, Manuel FernandezMolina, MD, Inmaculada Fierro, PhD, etal. Postoperative kidney oxygen saturation as a novel marker for acute kidney injury after adult cardiac surgery. The Journal of Thoracic and Cardiovascular Surgery, 17 Oct 2018, 157(6):2340-51.e3.

https://doi.org/10.1016/j.jtcvs.2018.09.115

11. Tholén M, Ricksten SE, Lannemyr L. Renal near-Infrared spectroscopy for assessment of renal oxygenation in adults undergoing cardiac surgery: A method validation study. J Cardiothorac Vasc Anesth. 2020 Dec; 34(12):3300-5. https://doi.org/10.1053/j.jvca.2020.04.044

12. Thakar CV, Liangos O, Yared JP, Nelson DA, Hariachar S, Paganini EP. Predicting acute renal failure after cardiac surgery: Validation and re-definition of a risk stratification algorithm. Hemodial Int. 2003 Apr 1;7(2):143-7. https://doi.org/10.1046/j.1492-7535.2003.00029.x

13. Fortescue EB, Bates DW, Chertow GM. Predicting acute renal failure after coronary bypass surgery: Crossvalidation of two risk-stratification algorithms. Kidney Int. 2000 Jun;57(6):2594-602. https://doi.org/10.1046/j.1523-1755.2000.00119.xq

14. Fischer UM, Weissenberger WK, Warters RD, Geissler HJ, Allen SJ, Mehlhorn U. Impact of cardiopulmonary bypass management on postcardiac surgery renal function. Perfusion. 2002 Nov;17(6):401-6. https://doi.org/10.1191/0267659102pf610oa

15. Slogoff S, Reul GJ, Keats AS, Curry GR, Crum ME, Elmquist BA, Giesecke NM, Jistel JR, Rogers LK, Soderberg JD, et al. Role of perfusion pressure and flow in major organ dysfunction after cardiopulmonary bypass. Ann Thorac Surg. 1990 Dec;50(6):911-8. https://doi.org/10.1016/0003-4975(90)91118-U

16. Ruf B, Bonelli V, Balling G, Hörer J, Nagdyman N, Lorenz Braun $S$, et al. Intraoperative renal near-infrared spectroscopy indicates developing acute kidney injury ininfants undergoing cardiac surgery with cardiopulmonary bypass: a case-control study. Crit Care. 2015 Jan 29;19(1):27. https://doi.org/10.1186/s13054-015-0760-9

17. Provenchere S, Plantefeve G, Hufnagel G, Vicaut E., De Vaumas C, Lecharny JB, et al. Renal dysfunction after cardiac surgery with normothermic cardiopulmonary bypass: Incidence, risk factors and effect on clinical. outcome. Anesth Analg. 2003 May;96(5):1258-64. https://doi.org/10.1213/01.ANE.0000055803.92191.69 